\title{
The Effect of Similarity between Elemental Stimuli and Compounds in Olfactory Patterning Discriminations
}

\author{
Nina Deisig, ${ }^{1}$ Harald Lachnit, ${ }^{2,4}$ and Martin Giurfa ${ }^{3}$ \\ ${ }^{1}$ Neurobiology, Institute of Biology, Free University of Berlin, D-14195 Berlin, Germany; ${ }^{2}$ Department of Psychology, Philipps-University of \\ Marburg, D-35032 Marburg, Germany; ${ }^{3}$ Lab. de Cognition Animale, Université Paul-Sabatier, 31062 Toulouse cedex 04, France
}

\begin{abstract}
We studied the ability of honeybees to discriminate between single odorants and binary olfactory mixtures. We analyzed the effect of the number of common elements between these two stimulus classes on olfactory discrimination. We used olfactory conditioning of the honeybees' proboscis extension reflex (PER), a paradigm in which odors can be associated with a reinforcement of sucrose solution. Bees were asked to discriminate reinforced from nonreinforced olfactory stimuli. They were trained with two elemental odors (A and $\mathrm{B}$ ) versus a binary olfactory mixture. The mixture was either $\mathrm{AB}$ (group 2CE, two common elements), AC (group 1CE, one common element A), or CD (group 0CE, no common element). Three groups followed a positive patterning schedule (mixture reinforced and elements nonreinforced: groups 2CE+, 1CE+, and 0CE+) and three other groups a negative patterning schedule (mixture nonreinforced and elements reinforced: groups 2CE-, 1CE-, and OCE-). We showed that a reduction of similarity (number of common elements) between elemental odors and compounds enhanced the ability to discriminate elements from compounds and that the kind of compound processing used by the bees supports theories that assume nonelemental compound processing (i.e., that exclude the mere summation of the elemental associative strengths upon compound presentation).
\end{abstract}

Animals are rarely confronted with isolated stimuli but have to learn associations usually involving compound stimuli. Such compounds may consist of few or many components. These circumstances raise the question of how animals process compound stimuli. Do they care about the elemental composition of the stimuli or do they process a compound as a whole?

There are four different ways of interpreting compound processing. (1) Pure elemental theories (e.g., Rescorla and Wagner 1972) assume that the total associative strength of a compound stimulus is based on the mere summation of the associative strengths of its elements. (2) The unique-cue approach (Rescorla 1972, 1973; Whitlow and Wagner 1972) assumes that a compound consists of its elements, plus an additional configural stimulus that is unique to the compound but can otherwise be dealt with as an additional element. (3) Configural theories (e.g., Pearce 1987 , 1994) postulate that the elements of a compound collectively enter into one single association. According to this theory, generalization of associative strength between the elements and the compound occurs depending on their similarity. (4) An extreme configural theory adheres to the

${ }^{4}$ Corresponding author.

E-MAIL Lachnit@mailer.uni-marburg.de; FAX 49-6421-2826621. Article and publication are at http://www.learnmem.org/cgi/doi/ $10.1101 / 1 \mathrm{~lm} .41002$. basic assumption of the configural theory but pushes the reasoning to the extreme in postulating that a compound is coded as a new stimulus (Gestalt) that is totally unrelated to its elements (for a comparison of the extreme configural and configural point of views, see Williams and Braker 1999).

Pure elemental theories assuming additive combinations of associative strengths of components encounter difficulties in explaining the solving of patterning discriminations. A positive patterning discrimination (i.e., the animal responds to a reinforced compound $\mathrm{AB}$ and not to its single nonreinforced elements $A$ and B) can be solved through elemental processing. The associative strengths of the elements could be subthreshold for the response but once added onto compound presentation, they might result in a suprathreshold associative strength. Such a summation would result in higher response to the compound than to either element. Contrary, a negative patterning discrimination (i.e., the animal responds to the single reinforced elements $\mathrm{A}$ or $\mathrm{B}$ but not to the nonreinforced compound $\mathrm{AB}$ ) can only be solved if the animal is capable of configural processing. Summation of the elemental excitatory strengths on compound presentation would always result in higher response to the compound and would be incompatible with a decrease in the response to the nonreinforced compound.

LEARNING \& MEMORY 9:112-121 @ 2002 by Cold Spring Harbor Laboratory Press ISSN1072-0502/02 \$5.00

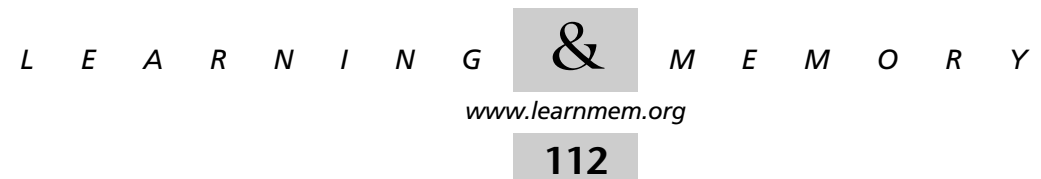


Assuming that in compound trials a unique cue is present in addition to the elements (Rescorla 1972, 1973; Whitlow and Wagner 1972) allows us to explain why animals can solve both positive and negative patterning without abandoning an elemental summation principle. Solving negative patterning is explained by assuming that the separate elements (the reinforced conditioned stimuli, or CSs+) gain excitatory strength through pairing with the unconditioned stimulus (US). On the other hand, omission of the US on compound presentation (the nonreinforced conditioned stimulus, or CS-) causes the unique cue to gain enough inhibitory strength to counterbalance the excitatory strengths of the elements. Solving positive patterning is explained by assuming that the unique cue acquires excitatory strength via pairing with the US on compound trials, whereas omission of the US on element trials causes the separate elements to remain neutral or to become inhibitory.

Solving of patterning discriminations can also be explained by configural theories (Pearce 1987, 1994). If animals only use configural information about the entire compound, differentiation between elements and compound is straightforward. Generalization between the compound and its elements, however, acts against the discrimination task. The more similar the stimuli are (i.e., the more elements they have in common), the more generalization and therefore the less differentiation takes place. An extreme configural theory excludes generalization as it assumes that a compound is totally different from its components. Under such an assumption, solving of patterning discriminations is easy. A wide range of empirical outcomes is in agreement with the first three approaches (e.g., Lachnit et al. 2001).

The honeybee (Apis mellifera L.) offers an adequate model to study the mechanisms underlying compound processing. Bees forage in a complex environment in which they are confronted with a plethora of multimodal sensory stimuli characterizing their food sources, the flowers, and their nest (Menzel 1985; Menzel and Giurfa 2001). Within the darkness of the hive, they orient in a complex and rich olfactory world. Sensory capacities and motor performances are highly developed. Bees see the world in color, perceive shapes and patterns, and resolve movements with a high temporal resolution (Giurfa and Menzel 1997; Giurfa and Lehrer 2001). Their olfactory sense is well developed (Vareschi 1971; Laska et al. 1999) and their mechanosensory perception is also extremely rich (Erber et al. 1998). Furthermore, bees efficiently learn and memorize sensory information of their environment (Menzel et al. 1993; Menzel and Müller 1996; Menzel 1999; Menzel and Giurfa 2001).

Harnessed honeybees offer a helpful preparation for studying the principles governing classical conditioning of the proboscis extension reflex (PER; Takeda 1961; Bitterman et al. 1983). When the antennae of a hungry bee are touched with sucrose solution, the animal reflexively ex- tends its proboscis to suck the sucrose. Odors to the antennae do not release such a reflex in naive animals. If, however, an odor is presented immediately before sucrose solution (forward pairing), an association is formed that enables the odor to release the PER in a following test. This effect is clearly associative and involves classical conditioning (Bitterman et al. 1983). Thus the odor can be viewed as the CS and the sucrose solution as the US.

Using such a preparation and binary olfactory compounds as CSs, we were able to show that honeybees differentiate reinforced from nonreinforced stimuli in positive and negative patterning discriminations (Deisig et al. 2001). The variation of the ratio between the presentations of the reinforced and nonreinforced stimuli modulated the amount of differentiation. The successful differentiation found for negative patterning cannot be explained by the elemental summation principle. Additionally, in the positive patterning discrimination, the response to the reinforced compound increased, whereas the response to nonreinforced elements decreased. Therefore summation of the associative strengths of the single elements cannot explain the enhanced responsiveness to the compound. Thus, configural representations should also be involved in the positive patterning discrimination (Deisig et al. 2001). As the processing strategy adopted by the bees to solve the patterning discrimination problems in olfactory PER conditioning remained unclear (Deisig et al. 2001), we extended our studies to further clarify this aspect. In particular, we asked whether the use of nonelemental processing by bees depends upon the type of discrimination problem. The present work was designed to study the effect of varying the number of common elements in two classes of stimuli (single odors and binary olfactory compounds). Bees were trained with two elemental odors, $\mathrm{A}$ and $\mathrm{B}$, that had to be discriminated from a binary olfactory compound. In a first group, bees were trained with the compound $\mathrm{AB}$ (two common elements $\mathrm{A}$ and $\mathrm{B}$ ), in a second group with the compound $\mathrm{AC}$ (one common element $\mathrm{A}$ ), and in a third group with the compound CD (no common element). For each group, training was performed according to either a positive (compound reinforced and elements nonreinforced) or a negative patterning schedule (compound nonreinforced and elements reinforced). In both cases, the reduction of the number of common elements between CS+ and CSfrom the first to the third group should decrease the demands for nonelemental processing to solve the discrimination. We examined the hypothesis that a maximal number of common elements (two) between both stimulus classes (i.e., a typical patterning experiment) might promote nonelemental processing, whereas the absence of common elements between both classes might promote elemental processing. To decide between the four rival explanations, the groups trained according to a positive patterning schedule received nonreinforced test trials with an element $C$,

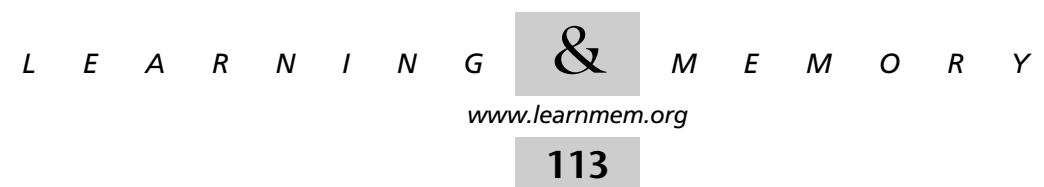


whereas those trained according to a negative patterning schedule received nonreinforced test trials with a compound $\mathrm{BC}$. The rationale for choosing these test stimuli is described below.

\section{RESULTS}

\section{Experiment 1: Nonreinforced Elements and Reinforced Compounds (Positive Patterning)}

In experiment 1 we investigated the impact of similarity (number of common elements) between nonreinforced elements (CSs-) and a reinforced compound (CS+) on response differentiation. The number of reinforced trials and the number of nonreinforced trials was eight. We compared the performance of three groups: group $2 \mathrm{CE}+, \mathrm{A}-, \mathrm{B}-$, and $\mathrm{AB}+$; group $1 \mathrm{CE}+, \mathrm{A}-, \mathrm{B}-$, and $\mathrm{AC}+$; and group $0 \mathrm{CE}+, \mathrm{A}-$, $\mathrm{B}-$, and $\mathrm{CD}+$. The discrimination of group $2 \mathrm{CE}+$ is a positive patterning discrimination.

Figure 1a shows for each of the three groups (upper panel, group 2CE+; middle panel, group 1CE+; lower panel, group OCE+) the acquisition of conditioned responses (\%PER) to the compound (CS+) and to the elements A- and B- (CSs-) along four blocks of trials. Figure $1 \mathrm{~b}$ shows response to a nonreinforced element $(\mathrm{C}-$ ) in a test phase following acquisition. All groups showed increasing response differentiation between CS+ and CSs- along training (Fig. 1a). The response differentiation in group OCE+ was larger than in group 2CE+. Response differentiation of group 1CE+ was intermediate.

\section{Acquisition}

To compare the amount of differentiation reached at the end of acquisition (Fig. 1a) a group $\times$ stimulus $(3 \times 3)$ analysis of variance (ANOVA) for block 4 was computed. The main effect of group $\left(F_{2}, 108=2.92 ; P>0.05\right)$ was marginally nonsignificant, whereas the main effect of stimulus $\left(F_{2}\right.$, $216=203.26 ; P<0.001)$ was significant. Because the interaction group $\times$ stimulus was significant $\left(F_{4,216}=10.07\right.$; $P<0.001$ ), we computed simple effects for stimulus and group.

All three groups showed significantly $(P<0.001)$ larger responses to the CS+ than to either of the CSs- (group 2CE+, $F_{2,216}=30$; group $1 \mathrm{CE}+, \quad F_{2}, \quad 216=73.63$; and group 0CE+, $F_{2,216}=119.78$ ). With decreasing similarity, the amount of differentiation in block 4 increased. A Tukey test (honestly significant difference $[\mathrm{HSD}]=16.25)$ showed that the response to $\mathrm{A}-(M=27.02)$ in group $2 \mathrm{CE}+$ was similar to the response to $\mathrm{B}-$ $(M=29.73)$. The response to either element was smaller than to the compound $\mathrm{AB}+(M=74.32)$. In group $1 \mathrm{CE}+$ the response to $\mathrm{B}-(M=0)$ was smaller than to A$(M=24.32)$, which by itself was smaller than the response to the compound $\mathrm{AC}+$ $(M=81.08)$. In group $0 \mathrm{CE}+$ the response to A- $(M=0)$ was similar to $\mathrm{B}-(M=2.7)$, but the response to either element was smaller than the response to the compound $\mathrm{CD}+$ $(M=93.24)$.

The groups differed in responding to $\mathrm{A}-\left(F_{2}, \quad 108=7.84 ; P<0.001\right)$, to $\mathrm{B}-$ $\left(F_{2,108}=9.56 ; P<0.001\right)$, and to the compounds $\mathrm{AB}+, \mathrm{AC}+$, or $\mathrm{DC}+\left(F_{2,108}=3.25\right.$; $P<0.05)$. A Tukey test $(\mathrm{HSD}=19.68)$ showed that response to A- in group 2CE+ $(M=27.02)$ and in group $1 \mathrm{CE}+(M=24.32)$ was similar but was significantly larger in both groups than in group 0CE+ $(M=0)$. The response to $\mathrm{B}-$ in group $1 \mathrm{CE}+(M=0)$ and in group $0 \mathrm{CE}+(M=2.7)$ was similar but was significantly smaller in both groups than in group $2 \mathrm{CE}+(M=29.73)$. The re-

Figure 1 Conditioned proboscis extension response (\%PER) along trials of a positive patterning discrimination with different numbers of common elements in two classes of stimuli (single odors and binary olfactory compounds). (a) Course of \%PER to the nonreinforced elements $\mathrm{A}$ and $\mathrm{B}$ (open symbols, CSs-) and to the reinforced compounds $\mathrm{AB}$ $\mathrm{AC}$, or $\mathrm{CD}$ (filled symbols, $\mathrm{CS}+$ ) during acquisition along four blocks of two trials each. (b) Course of \%PER to a nonreinforced test element (open circles, C-) along six test trials. The upper panels show response during acquisition and test for group $2 \mathrm{CE}+$, with two common elements between the two classes of stimuli $(\mathrm{AB}+\mathrm{vs}$. $\mathrm{A}-, \mathrm{B}-)$. The middle panels show response for group $1 \mathrm{CE}+$ with one common element between the two classes of stimuli (AC+ vs. A-,B-). The lower panels show response for group $0 \mathrm{CE}+$, with no common element between the two classes of stimuli (CD+vs. A-, B-).

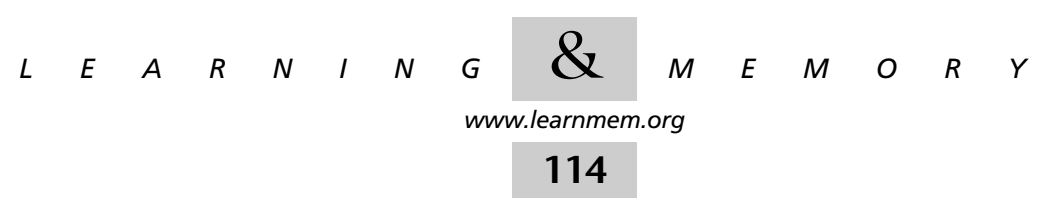


sponse to the compound in group 0CE+ $(M=93.24)$ was larger (nearly significant) than in group $2 \mathrm{CE}+(M=74.32)$. The response to the compound in group $1 \mathrm{CE}+(M=81.08)$ was intermediate.

The response to nonreinforced elements that were part of the reinforced compound (A in group $1 \mathrm{CE}+, \mathrm{A}$ and $\mathrm{B}$ in group 2CE+) was larger than the response to elements that were never presented in a compound (A and B in group OCE+, B in group 1CE+).

\section{Test}

A group $\times$ trial $(3 \times 6)$ ANOVA was computed for the nonreinforced presentations of $\mathrm{C}-$ (Fig. 1b). We found a significant main effect of group $\left(F_{2,108}=7.96 ; P<0.001\right)$, as well as a significant main effect of trial $\left(F_{5,540}=10.25\right.$; $P<0.001)$. The interaction group $\times$ trial was not significant $\left(F_{10,540}=1.73 ; P>0.09\right)$. Both groups $1 \mathrm{CE}+$ and $0 \mathrm{CE}+$ showed a significant decrease in the response to $\mathrm{C}-$ along blocks, whereas group 2CE + did not $(\mathrm{HSD}=17.33$ for all comparisons). The response to the first $\mathrm{C}-$ in group $1 \mathrm{CE}+$ $(M=40.54)$ and group 0CE+ $(M=54.05)$ was similar (HSD $=24.35)$ but higher than that in group 2CE+ $(M=8.11)$.

\section{Linking Acquisition and Test}

We compared the response to the last reinforced compound in acquisition (block 4) with the response to the first nonreinforced presentation of $\mathrm{C}$ - in both groups, in which $\mathrm{C}$ was trained as a part of the compound (group 1CE+ and group OCE + ). A $2 \times 2$ (group $\times$ stimulus) ANOVA showed that the main effect of group $\left(F_{1,72}=2.86 ; P>0.09\right)$ and the group $\times$ stimulus interaction $(F<1)$ were not significant. The main effect of stimulus, however, was significant $\left(F_{1,72}=47.08 ; P<0.001\right)$. Post hoc comparisons showed that the response to $\mathrm{AC}+(M=81.08)$ in group $1 \mathrm{CE}+$ was larger than the response to $\mathrm{C}-(M=40.54)$. In group $0 \mathrm{CE}+$ the response to $\mathrm{CD}+(M=93.24)$ was larger than the response to $\mathrm{C}-(M=54.05$; HSD $=16.38)$. The comparison $\mathrm{AC}+$ versus $\mathrm{CD}+$ showed that the response to $\mathrm{AC}+$ $(M=81.08)$ and $\mathrm{CD}+(M=93.24)$ differed $(\mathrm{HSD}=11.99)$. Also the response to $\mathrm{C}-$ in both groups differed (group $1 \mathrm{CE}+, M=40.54$; group 0CE+, $M=54.05$; HSD = 11.99).

\section{DISCUSSION}

The interpretation of the results of this experiment in the light of the different learning theories presented above is rendered difficult by the fact that animals of group $1 \mathrm{CE}+$ (Fig. 1, middle panel) may have not reached asymptotic levels in the acquisition. Our last analysis (see Linking Acquisition and Test below), as well as the fact that in group $1 \mathrm{CE}+$ the response to $\mathrm{A}-$ was larger than the response to $\mathrm{B}-$, support this interpretation. It could be possible that asymptotic learning requires more than four nonreinforced exposures to A when A is also part of the reinforced com- pound. This would explain the level of responses to A and $\mathrm{B}$ at the end of training in group 2CE+ (Fig. 1a, upper panel) and to $\mathrm{A}$ in group 1CE+ (Fig. 1a, middle panel). Due to this empirical problem, we did not attempt to interpret the results of this experiment in the frame of the different theories about compound learning. Note, however, that in an earlier study (Deisig et al. 2001) we showed that solving a positive patterning discrimination like the one trained in group 2CE+ of the current experiment involved some nonelemental processing.

\section{Experiment 2: Reinforced Elements and Nonreinforced Compounds (Negative Patterning)}

In experiment 2 we investigated the impact of similarity (number of common elements) between reinforced elements (CSs+) and a nonreinforced compound (CS-) on response differentiation. The number of reinforced trials and the number of nonreinforced trials was eight each. We compared the performance of three groups: group $2 \mathrm{CE}-, \mathrm{A}+$, $\mathrm{B}+$, and $\mathrm{AB}-$; group $1 \mathrm{CE}-, \mathrm{A}+, \mathrm{B}+$, and $\mathrm{AC}-$; and group OCE-, $\mathrm{A}+, \mathrm{B}+$, and $\mathrm{CD}-$. The discrimination of group $2 \mathrm{CE}-$ is a negative patterning discrimination.

Figure $2 \mathrm{a}$ shows the acquisition of conditioned responses (\%PER) to the compound (CS-) and to the elements $\mathrm{A}+$ and $\mathrm{B}+(\mathrm{CSs}+)$ for each of the three groups (upper panel, group 2CE-; middle panel, group 1CE-; lower panel, group 0CE-) along four blocks of trials. Figure $2 \mathrm{~b}$ shows the response to a new nonreinforced compound (BC-) in a test phase following acquisition. All three groups showed increasing response differentiation between CSs+ and CSalong training. The overall response differentiation in group 0CE- was larger than in group 2CE-. Group 1CE- showed intermediate response differentiation.

\section{Acquisition}

We compared the amount of differentiation reached at the end of acquisition (block 4$)$ by a group $\times$ stimulus $(3 \times 3)$ ANOVA (Fig. 2a). The main effect of group $\left(F_{2,108}=7.56\right.$; $P<0.001)$ and the main effect of stimulus $\left(\mathrm{F}_{2}, 216=84.6\right.$; $P<0.001)$ were significant. As the interaction group $\times$ stimulus $\left(F_{4,216}=3.95 ; P<0.006\right)$ was also significant, we computed simple effects for stimulus and group.

All three groups showed significantly $(P<0.001)$ larger responses to either CSs+ than to the CS- (group 2CE-, $F_{2,216}=13.73$; group $1 \mathrm{CE}-, F_{2,216}=25.2$; group 0CE-, $F_{2,216}=53.56$ ). With decreasing similarity, the amount of response differentiation reached in block 4 increased. A Tukey test $(\mathrm{HSD}=20.1)$ showed that the response to $\mathrm{A}+$ in group 2CE- $(M=37.84)$ did not differ from the response to $\mathrm{B}+(M=45.95)$, but the response to either element was larger than the response to the compound $\mathrm{AB}-(M=4.05)$. In group $1 \mathrm{CE}-$ the response to $\mathrm{B}+(M=62.16)$ was larger than the response to $\mathrm{A}+(M=40.54)$, which by itself was

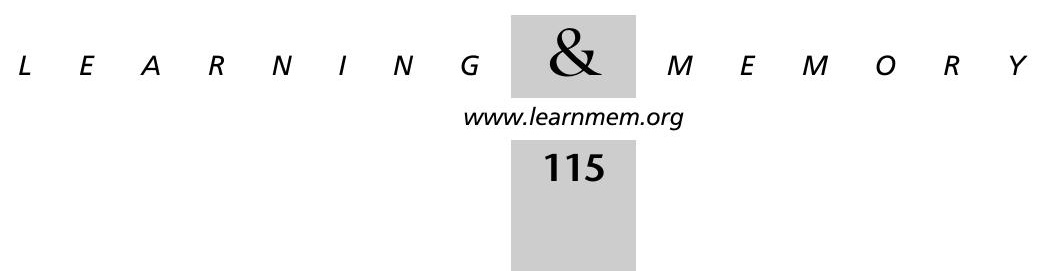




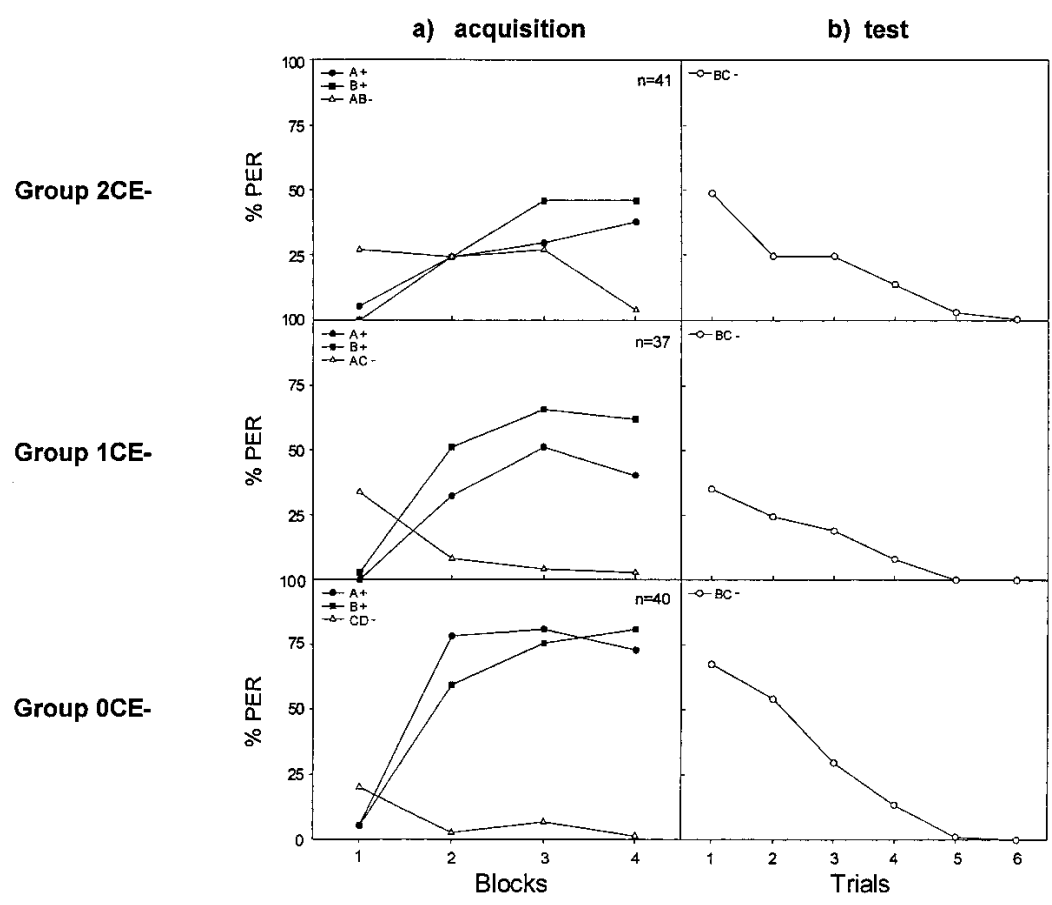

Figure 2 Conditioned proboscis extension response (\% PER) along trials of a negative patterning discrimination with different numbers of common elements in two classes of stimuli (single odors and binary olfactory compounds). (a) Course of \%PER to the reinforced elements $\mathrm{A}$ and $\mathrm{B}$ (filled symbols, $\mathrm{CSs}+$ ) and to the nonreinforced compounds $\mathrm{AB}$, $\mathrm{AC}$, or $\mathrm{CD}$ (open symbols, CS-) during acquisition along four blocks of two trials each (b) Course of \%PER to a nonreinforced test compound (open circles, BC-) along six test trials. The upper panels show response during acquisition and test for group 2CE-, with two common elements between the two classes of stimuli (AB-vs. A+, B+). The middle panels show response for group 1CE- with one common element between the two classes of stimuli (AC- vs. A+, B+). The lower panels show response for group 0CE-, with no common element between the two classes of stimuli (CD- vs. $A+, B+)$.

group. All three groups (group 2CE-, $F_{5}$, $540=12.51 ;$ group $1 \mathrm{CE}-, F_{5}, 540=7.88$; group 0CE-,$\left.F_{5,504}=27.72\right)$ showed significantly $(P<0.001)$ decreasing responses to $\mathrm{BC}-$ along trials. However, the groups differed in their response to the first presentation of $\mathrm{BC}-\left(F_{2,108}=7.51 ; P<0.001\right)$. A Tukey test $(\mathrm{HSD}=22.02)$ showed that the response in group 2CE- $(M=48.65)$ shortly failed to be significantly smaller than the response in group 0CE- $(M=67.57)$. Group $1 \mathrm{CE}-(M=35.14)$ differed from group 0CEbut not from group 2CE-.

\section{Linking Acquisition and Test}

For all three groups, we compared the response to the last nonreinforced compound presentation (block 4) with the last reinforced presentation of $\mathrm{B}+$ (block 4) and the first nonreinforced presentation of BC-. A $3 \times 3$ (group $\times$ stimulus) ANOVA yielded significant differences for the main effect of group $\left(F_{2,108}=4.4 ; P<0.02\right)$, stimulus $\left(F_{2,216}=95.91 ; P<0.001\right)$, and group $\times$ stimulus interaction $\left(F_{4,216}=4.59 ; P<0.002\right)$.

We, therefore, computed simple effects for stimulus and group. All three groups (group 2CE-, $F_{2,216}=19.72$; group 1CE-, $F_{2,216}=27.96 ;$ group 0CE,$\left.- F_{2,216}=57.43\right)$ showed significantly $(P<0.001)$ larger responses to $\mathrm{B}+$ and $\mathrm{BC}-$ than to the nonreinforced compound (group 2CE-, $\mathrm{AB}-$; group 1CE-, AC-; group 0CE-, CD-). A Tukey test $(\mathrm{HSD}=18.86)$ showed that in

larger than the response to the compound AC- $(M=2.7)$. In group 0CE- the response to $\mathrm{A}+(M=72.97)$ did not differ from the response to $\mathrm{B}+(M=81.08)$, but the response to either element was larger than the response to the compound CD- $(M=1.35)$.

The groups differed in the response to $\mathrm{A}+\left(F_{2,108}=9.1\right.$; $P<0.001)$. A Tukey test $(\mathrm{HSD}=23.94)$ showed that the response in group 2CE- $(M=37.84)$ and group 1CE( $M=40.54)$ was similar but was significantly smaller than in group 0CE- $(M=72.97)$. The response to $\mathrm{B}+$ and to the nonreinforced compound will be analyzed later in an ANOVA, including the response to the test compound BC-.

\section{Test}

A group $\times$ trial $(3 \times 6)$ ANOVA was computed for the nonreinforced presentations of $\mathrm{BC}-$ (Fig. 2b). We found a significant main effect of group $\left(F_{2}, 108=4.11 ; P<0.02\right)$, trial $\left(F_{5,540}=43.68 ; P<0.001\right)$, and of the interaction group $\times \operatorname{trial}\left(F_{10,540}=2.22 ; P<0.03\right)$.

Therefore, we computed simple effects for trial and group 2CE- the response to $\mathrm{BC}-(M=48.65)$ did not differ from the response to $\mathrm{B}+(M=45.95)$, but the response to both was larger than the response to the compound $\mathrm{AB}-$ $(M=4.05)$. In group $1 \mathrm{CE}-$ the response to $\mathrm{BC}-(M=35.14)$ was smaller than the response to $\mathrm{B}+(M=62.16)$ and the response to $\mathrm{AC}-(M=2.7)$ was smaller than the response to both $\mathrm{B}+$ and $\mathrm{BC}-$. In group $0 \mathrm{CE}-$ the response to $\mathrm{BC}-$ $(M=67.57)$ did not differ from the response to $\mathrm{B}+$ ( $M=81.08)$, but the response to both was larger than the response to $\mathrm{CD}-(M=1.35)$.

The groups differed in their response to $\mathrm{B}+\left(F_{2}\right.$, $108=7.23 ; P<0.002)$ and to BC $-\left(F_{2,108}=6.21 ; P<0.003\right)$ but not in their response to the nonreinforced compound $(F<1)$. A Tukey test (HSD $=24.2)$ showed that the response to $\mathrm{B}+$ in group $2 \mathrm{CE}-(M=45.95)$ was significantly lower than the response to $\mathrm{B}+$ in group 0CE- $(M=81.08)$. Group $1 \mathrm{CE}-(M=62.16)$ showed an intermediate response level to $\mathrm{B}+$. The response to $\mathrm{BC}-$ in group 2CE$(M=48.65)$ was not significantly lower than the response to $\mathrm{BC}-$ in group 0CE- $(M=67.57)$. This was also the case

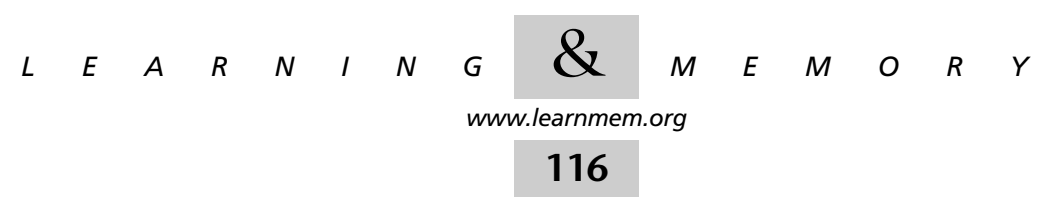


for group 1CE- $(M=35.14)$. The difference between group 2CE- and group 1CE- was not significant.

\section{General Discussion}

The acquisition (Fig. 2a) of experiment 2 showed that the response to reinforced elements that were part of the nonreinforced compound (A in group 1CE-; A and B in group 2CE-) was smaller than the response to elements that were never presented in a compound (A and B in group 0CE-; B in group $1 \mathrm{CE}-$ ). This finding contradicts a pure elemental theory because the response to the compounds was even smaller than the response to the element(s) in common. This is particularly evident in the case of group 2CE- in which such an elemental account assumes summation of the excitatory strengths of $\mathrm{A}+$ and $\mathrm{B}+$ on compound presentation, a fact that could never result in a decrease in the response to $\mathrm{AB}-$. The results of the acquisition also reject the extreme configural theory because, for this theory, each of the three compounds $(\mathrm{AB}, \mathrm{AC}$, and $\mathrm{CD})$ constitutes an entity that differs from the elements $A$ and $B$. Thus differentiation between compound and elements should be the same overall. As this was not the case, we exclude the extreme configural theory as an explanation for the acquisition of experiment 2.

Predictions of both the unique-cue theory and Pearce's configural theory, however, are in accordance with the acquisition data. The unique-cue theory could explain successful differentiation in the acquisition as such a cue might carry the inhibitory associative strength of the compound. In accordance with Pearce's configural theory, our data show that generalization between the compound and its elements depends on their similarity (i.e., number of common elements).

The combined analysis of acquisition and test allows rejecting again the extreme configural theory. This theory predicts that the response to $\mathrm{BC}-$ in all three groups (2CE-, $1 \mathrm{CE}-$, and $\mathrm{OCE}-$ ) should be equal because in all three cases $\mathrm{BC}$ would be a new configuration, different from all stimuli known. This was not the case, as the response to $\mathrm{BC}-$ varied across the three groups.

For deciding between the three remaining theories (pure elemental, unique-cue, and Pearce's configural theory), we analyzed each group separately. For group $2 \mathrm{CE}-$, the three theories predict that the response to $\mathrm{BC}-$ should be larger than the response to $\mathrm{AB}-$. Furthermore, both the elemental and the unique-cue theories predict that the response to $\mathrm{BC}-$ should equal the response to $\mathrm{B}+$, whereas Pearce's configural theory predicts that the response to $\mathrm{B}+$ should be higher than the response to $\mathrm{BC}-$, as the latter constitutes a new configuration that nevertheless includes $\mathrm{B}$. In group $2 \mathrm{CE}-$, bees responded equally to $\mathrm{B}+$ and to BC- (Fig. 2a,b; upper panel). Therefore, Pearce's configural theory has to be rejected. From the two remaining theories that predicted such an outcome (pure elemen- tal and unique-cue) the pure elemental theory was already rejected because it cannot explain the acquisition data. Thus, only the unique-cue theory can account for the data of group 2CE-.

For group $1 \mathrm{CE}-$, the three theories predict that the response to $\mathrm{BC}-$ should be smaller than the response to $\mathrm{B}+$. This prediction was supported by the empirical data. The unique-cue approach and Pearce's configural theory predict that the response to $\mathrm{AC}-$ should be smaller than the response to $\mathrm{BC}-$, whereas the elemental theory predicts no difference because A and B should have the same excitatory strength at the learning asymptote. The empirical data show that bees responded more to $\mathrm{BC}-$ than to AC- (Fig. 2a,b, middle panel), a fact that rejects the pure elemental theory and supports both the unique-cue and Pearce's configural theory. Further experiments are necessary to decide between these two possibilities. However, results of group $1 \mathrm{CE}-$ show that a discrimination task $(\mathrm{A}+, \mathrm{B}+\mathrm{vs}$. $\mathrm{AC}-)$ that does not necessarily promote configural processing nevertheless may be solved using that kind of processing.

For group 0CE-, both the unique-cue theory and Pearce's configural theory predict that the response to CDshould be smaller than the response to $\mathrm{BC}-$, which by itself should be smaller than the response to $\mathrm{B}+$. The pure elemental theory predicts that the response to $\mathrm{BC}-$ should equal the response to $\mathrm{B}+$ because at the asymptote, $\mathrm{B}$ supports maximal associative strength, whereas $C$ supports no associative strength (therefore $\mathrm{B}=\mathrm{BC}$ ). Bees in group 0CEresponded more to $\mathrm{B}+$ than to $\mathrm{BC}-$ (Fig. 2a,b, lower panel). Although this difference failed to reach significance, it was close to it. Increasing the statistical power (i.e., more bees per group) might allow to reach significance, a fact that would support the predictions of the unique-cue and Pearce's configural theory. As for group $1 \mathrm{CE}-$, the results of group OCE- suggest that even in a discrimination task that can be solved in a pure elemental way (A, B vs. CD), bees may have adopted a nonelemental processing strategy.

Our work shows two major findings. First, a reduction of similarity (number of common elements) between elemental odors and compounds enhances the ability to discriminate elements and compounds. Second, the kind of processing used by the bees in experiment 2 (negative patterning design) excludes the pure elemental and the extreme configural theories; results of this experiment were consistent with the unique-cue theory and, partially, with Pearce's configural theory. In the case of experiment 1 (positive patterning), the kind of processing used by the bees to solve the discrimination problems could not be determined because asymptote of acquisition was most likely not reached by animals of two groups (2CE+ and 1CE+).

In the acquisition of both experiments 1 and 2 we found that differentiation between elemental odors and compounds improved with decreasing similarity (number

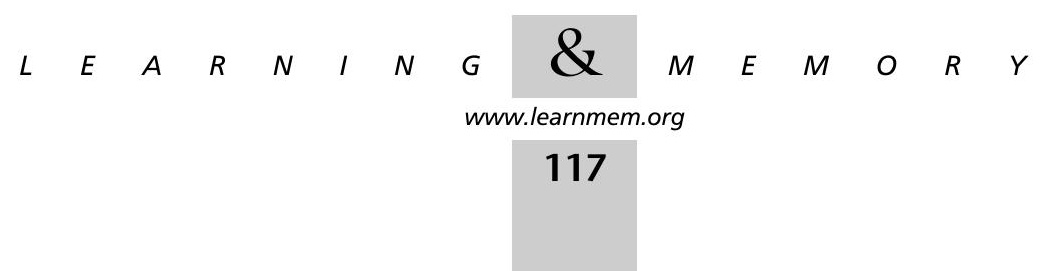


of common elements). Furthermore, the response to elemental odors that were part of the compound was higher (in the case of groups $\mathrm{CE}+$ ) or lower (in the case of groups CE-) than that observed for elemental odors that had not been part of a compound. The question then arises as to which strategy was used by the bees to achieve discrimination.

In a previous study (Deisig et al 2001), we partially answered this question. We showed that honeybees could differentiate reinforced and nonreinforced stimuli in positive and negative patterning discriminations (schedules corresponding to those of the actual groups $2 \mathrm{CE}+$ and $2 \mathrm{CE}-$ ). The successful differentiation found there for negative patterning could neither be explained by elemental summation nor by the unique-cue principle or Pearce's configural theory. We showed that nonelemental processing must have taken place to solve the discrimination problem. In the same way, results of the positive patterning discrimination also had supported the assumption that nonelemental representations are involved in this kind of discrimination. We thus had concluded that nonelemental representations (configural or unique-cue based) should have been involved both in negative and positive patterning discriminations.

The problem addressed in this study is related to the fact that a determining factor for adopting configural or elemental compound processing may be the difficulty inherent to the discrimination problem. Specifically, the number of common elements between compound and elements may drastically affect the ability of differentiating between them. If the number is high, similarity between compound and elements is also high and thus differentiation is difficult. This assumption was explicitly tested in our work. Bees confronted with an $\mathrm{AB}$ versus $\mathrm{A}, \mathrm{B}$ discrimination (groups 2CE+ and 2CE-) had two common elements between compound and elements, whereas bees confronted with a CD versus A, B discrimination (groups OCE+ and OCE-) had no common elements. For the former, the difficulty of the task may promote configural processing. For the latter, the discrimination is simple and may be based on elemental processing. Configural processing would then be unnecessary. Bees confronted with an $\mathrm{AC}$ versus $\mathrm{A}, \mathrm{B}$ discrimination (groups 1CE+ and 1CE-) face an intermediate situation. In this case, configural processing may take place.

Due to the lack of asymptotic level in experiment 1, only experiment 2 (negative patterning) allowed deciding among the pure elemental theory, the unique-cue theory, Pearce's configural theory, and the extreme configural theory. Table 1 summarizes our findings in relation to the support or rejection of these theories.

The results of all three groups neither supported the pure elemental theory nor the extreme configural theory. Pearce's configural theory was partially supported by data of groups 1CE- and OCE- but was not compatible with data of group 2CE-. Only the predictions of the unique-cue
Table 1. Support (+) or Rejection (-) of Compound

Processing Theories on the Basis of Experiment 2

\begin{tabular}{lcccc}
\hline & $\begin{array}{c}\text { Pure } \\
\text { elemental } \\
\text { theory }\end{array}$ & $\begin{array}{c}\text { Unique-cue } \\
\text { theory }\end{array}$ & $\begin{array}{c}\text { Pearce's } \\
\text { configural } \\
\text { theory }\end{array}$ & $\begin{array}{c}\text { Extreme } \\
\text { configural } \\
\text { theory }\end{array}$ \\
\hline Group 2EC- & - & + & - & - \\
Group 1EC- & - & + & + & - \\
Group 0EC- & - & + & + & - \\
\hline
\end{tabular}

theory were fully supported by all three groups. The fact that this theory, together with Pearce's configural one, was the most robust in accounting for our results indicates that honeybees do not use pure elemental strategies but rather rely on nonelemental strategies for solving negative patterning discriminations. Even results of discrimination tasks that would promote elemental processing (groups OCE-) could not be explained by the elemental theory and involved nonelemental processing.

Odorant concentration cannot account for solving the different discrimination tasks of our work. As mentioned below in Material and Methods, Pelz et al. (1997) showed that bees trained with our olfactory conditioning device do not use odorant concentration as the basis for discrimination. Furthermore, if in our experiments bees simply responded more to the higher concentration as they did in experiment 4 of Pelz et al. (1997), then in our positive patterning experiments (Fig. 1) the response to the elements should be higher than to the compound (in which both odorants were presented with about half the concentration relative to when they were presented alone). Last but not least, the data of our negative patterning experiments, too, contradicted the idea that the discrimination was based on concentration. First, the course of differentiation between CSs+ and CS- over blocks is inconsistent with the use of odorant concentration for solving the discrimination $\mathrm{A}+, \mathrm{B}+$ versus $\mathrm{AB}-$. In the first block of the acquisition of group 2EC- (see Fig. 2), the response to the compound $\mathrm{AB}$ was higher than that to the single odorants $\mathrm{A}$ and $B$. This suggests a summation effect that enhances the response to compound with respect to responses to the single elements and is exactly what we expect if bees use odorant quality in the response to the compound. If bees used odorant concentration, the opposite should be found throughout the blocks $(\mathrm{AB}<\mathrm{A}, \mathrm{B})$. Instead, in block 2 we found that the response to $\mathrm{AB}$ was equal to responses to $\mathrm{A}$ and $\mathrm{B}$. Only at the end of training, the response to $\mathrm{AB}$ was less than the response to A or B. Second, animals tested with BC- in group 2EC-, had experienced B but not C, which is therefore neutral and should not elicit responses (this is shown by the tests with $\mathrm{C}$ - in the positive patterning schedule; see Fig. 1). Thus, a $\mathrm{BC}-$ test in which the concentration of $\mathrm{B}$ was reduced to about half its original mag-

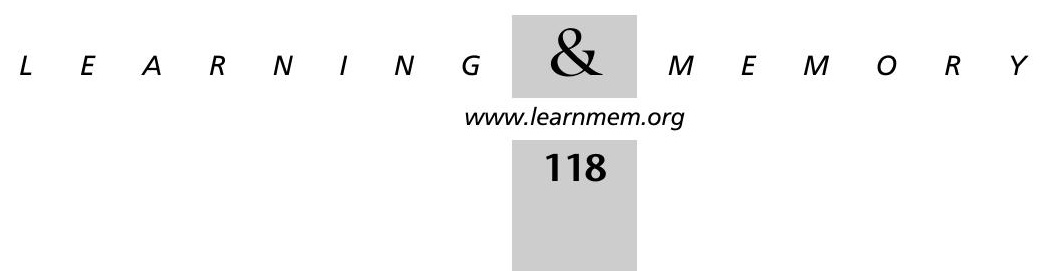


nitude should result in a response to $\mathrm{BC}-$ that should be half the response to $\mathrm{B}+$. This was not the case. The first response to $\mathrm{BC}-$ in the test was the same as that to $\mathrm{B}+$ in the last block of the acquisition.

Knowledge about the neural processing of odors yields more light about the true nature of olfactory compound processing in honeybees. Much is already known about the basic principles of olfactory coding at the level of the bee antennal lobe, the primary olfactory neuropile in the insect brain (Joerges et al. 1997; Galizia and Menzel 2000). In vivo optical recordings of the antennal lobe revealed that the activation patterns for binary odor mixtures include components of both single odorants. In general, this would support the idea of an elemental processing strategy (e.g., Rescorla and Wagner 1972) and contradicts an extreme configural theory. However, response profiles indicate inhibitory interactions at several glomeruli for the mixture response. Therefore, the patterns evoked are combinations of the single odorant responses that are not fully additive (Joerges et al. 1997). Such interactions could indicate the formation of singular codes for complex odor blends (Joerges et al. 1997) and therefore disagree with the pure elemental theory. Further optical recording studies performed in parallel with patterning discrimination problems might yield more light on the processing strategy used by bees.

Our findings are relevant in the ecological domain. The fact that honeybees can better discriminate olfactory elements and compounds when these are very different (e.g., A, B vs. CD) than when they are similar (e.g., A, B vs. AB) might affect flower discrimination by honeybee foragers and could be exploited by flowers that require pollinator visits to be fertilized. In a foraging context, differently rewarding flowers may partially overlap in their odorant composition. In that sense, configural processing of odor mixtures may allow identifying and discriminating a particular rewarding flower species from nonrewarding species having similar odors without errors due to enhanced generalization on the basis of components.

\section{METHODS}

Honeybees were caught at the entrance of outdoor hives at the beginning of each day. Each bee was placed in a small glass vial and immobilized by cooling it in a freezer. Individuals were mounted into restraining harnesses such that they could only move their antennae and mouthparts, including the proboscis (Takeda 1961; Bitterman et al. 1983). Animals were then kept undisturbed in a laboratory room for $\sim 2 \mathrm{~h}$. Ten minutes before the training session, each subject was checked for intact PER by touching one antenna with a toothpick imbibed with sucrose solution without subsequent feeding. Extension of the proboscis beyond a virtual line between the open mandibles was counted as a PER (unconditioned response). Animals that did not show the reflex $(<5 \%)$ were discarded for the experiments.

The US was always 1.25-M sucrose solution. The CSs were the odorants limonene, 2-octanol, methylsalicylate, and cineole (SIGMA). On each experimental day, $4 \mu \mathrm{L}$ of pure odorant were applied onto a fresh strip of filter paper. The paper strips were placed into a 1-mL plastic syringe and mounted in an odor-supplying device (Pelz et al. 1997). When the bee was placed in front of the device, it received a gentle, constant flow of clean air provided by a standard aquarium pump. Computer-driven solenoid valves (Lee Company) controlled airflow delivery. During periods of odorant delivery, the airflow was shunted through a syringe containing the odorant. In that way, a single odorant or a compound of two odorants was delivered to the bee. In the latter case, the valves corresponding to two different syringes were opened simultaneously, such that the airflow arriving at the antennae of the bee contained the two odors as a compound. An exhaust system was mounted behind the bees to remove odor-laden air. Between conditioning trials, bees were placed in front of a small van delivering a constant airflow comparable to that of the odor-supplying device. In that way, the mechanical airflow stimulation during training could not act as a predictor for the US.

Although it may be argued that in compound presentation bees are exposed to about half the magnitude of each odorant relative to when they were presented in isolation, it has been shown that bees are not able to use stimulus concentration as the basis to master olfactory discriminations (Pelz et al. 1997; see their experiment 4). Using the same conditioning device, Pelz et al. (1997) showed that bees failed in discriminating two different concentrations of the same odorant in a differential conditioning task. In this case, bees simply respond to the higher concentration, independent of its contingency (reinforced or nonreinforced). Although the concentration differences used by Pelz et al. (1997) largely exceeded the difference created by our device, bees were unable to use odorant concentration as a basis for discrimination.

At the beginning of each trial the subject was placed in front of the odor-supplying device for $15 \mathrm{sec}$ to allow familiarization with the training situation. Thereafter the CS was presented for $6 \mathrm{sec}$. In reinforced trials, the US onset occurred $3 \mathrm{sec}$ after CS onset. Both antennae were lightly touched with a toothpick imbibed with the sucrose solution and after proboscis extension the bee was allowed to feed for $3 \mathrm{sec}$. Therefore, the interstimulus interval was $3 \mathrm{sec}$ and the overlap between CS and US was also $3 \mathrm{sec}$. Nonreinforced trials consisted of 6 sec CS presentation without reward. After each conditioning trial, animals were returned to their resting position. The intertrial interval was $8 \mathrm{~min}$.

During acquisition, as well as in the subsequent test phase, we recorded whether a bee extended its proboscis after onset of the odor (CS) and before presentation of the sucrose solution (US) in the case of reinforced trials, such that the anticipatory response recorded could not have been evoked directly by the US. The criteria for the occurrence of a conditioned response were the same as for the unconditioned one (extension of the proboscis beyond a virtual line between the open mandibles), except that it should occur in response to the olfactory stimulation. Multiple responses during a CS were counted as a single PER. After completing the training session, all animals were again checked for PER. If an animal did not respond, it was discarded $(<10 \%)$. The same was true for animals that never or always responded during conditioning.

\section{Experimental Design}

\section{Acquisition}

Experiments were designed to study the effect of varying the number of common elements in the two classes of stimuli (single odors and binary olfactory compounds). Bees were trained to discrimi-

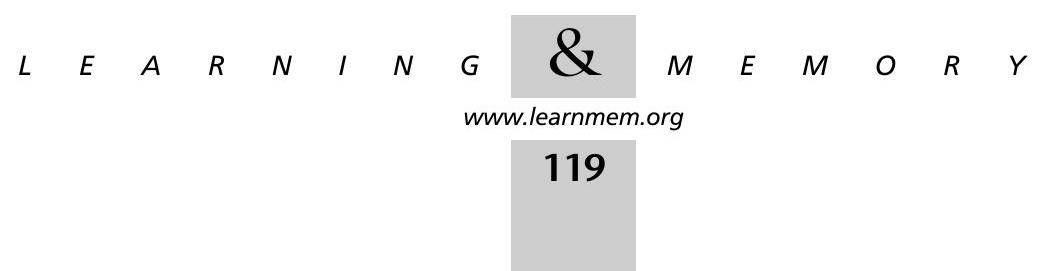


nate two elemental odors, A and B, from a binary olfactory compound. Training was performed according to a positive (compound reinforced and elements nonreinforced) or a negative patterning schedule (compound nonreinforced and elements reinforced). In both cases, three groups were established. In a first group (group 2CE, two common elements), bees were trained with a compound $\mathrm{AB}$ (two common elements, A and B). Bees from this group had thus to differentiate $\mathrm{AB}$ from $\mathrm{A}$ and $\mathrm{B}$, a discrimination which corresponded to a typical positive or negative patterning design, depending on the reinforced or nonreinforced nature of the compound and the elements. In a second group (group 1CE, one common element), bees were trained with a compound AC (one common element, A). Bees from this group had to differentiate AC from A and B. In a third group (group 0CE, no common elements), bees were trained with a compound $\mathrm{CD}$ (no common element). Bees from this group had to differentiate $\mathrm{CD}$ from $\mathrm{A}$ and $\mathrm{B}$. The reduction of the number of common elements between $\mathrm{CS}+$ and CS- from group 2CE to group OCE should decrease the demands for nonelemental processing to solve the discrimination.

The two odorants limonene and 2-octanol were randomized as $\mathrm{A}$ and $\mathrm{B}$; the odorants methylsalicylate and cineole were randomized as $C$ and $D$. Bees received a total of 16 training trials with four presentations of $\mathrm{A}$, four presentations of $\mathrm{B}$, and eight presentations of the compound ( $\mathrm{AB}, \mathrm{AC}$, or $\mathrm{CD}$ ). Within each group the sequence of CS+ and CS- trials was randomized and changed for each day. Each group consisted of 37 bees.

\section{Test}

After acquisition, bees were tested in six consecutive nonreinforced trials (intertrial interval, $8 \mathrm{~min}$ ). The three groups of bees trained according to positive patterning were given six $\mathrm{C}-$ trials. $\mathrm{C}$ was chosen to measure possible divergences in response as it was unknown to the first group $(\mathrm{AB}+)$ and potentially excitatory to the second and third groups ( $\mathrm{AC}+$ and $\mathrm{CD}+$, respectively). The three groups of bees trained according to negative patterning were given six BC- trials. The potentially inhibitory element $\mathrm{C}$ (at least for groups 1CE- and OCE-) was combined with $\mathrm{B}$ (excitatory in all groups), because a summation test is one conventional way for the examination of an inhibitor. Limonene and 2-octanol were randomized as B, whereas methylsalicylate and cineole were randomized as $\mathrm{C}$.

Experiments were run in an alternating fashion, that is, one day was assigned to one of the positive patterning groups and the next day to one of the negative patterning groups. On average, 20 bees were trained per day. As for each group, $\sim 40-60$ bees were trained, a complete group ran $\sim 2-3 \mathrm{~d}$.

\section{Data Transformation and Statistical Analyses}

We measured the percentage of conditioned responses (\%PER) separately in successive CS+ trials (omitting the randomly interspersed CS- trials) and in successive CS- trials (omitting the randomly interspersed CS+ trials).

In the positive patterning schedules, bees were given four Aand four $\mathrm{B}-$ presentations and eight reinforced compound presentations $(\mathrm{AB}+, \mathrm{AC}+$, or $\mathrm{CD}+)$. Data were grouped to obtain four blocks of two CS- trials and four blocks of two CS+ trials. In the negative patterning schedule, bees were given four $\mathrm{A}+$ and four $\mathrm{B}+$ presentations and eight nonreinforced compound presentations $(\mathrm{AB}-, \mathrm{AC}-$, or $\mathrm{CD}-)$. Data were again grouped to obtain four blocks of two CS+ trials and four blocks of two CS- trials.

For all groups, ANOVAs were used for between-group, as well as within-group, comparisons. Although ANOVA is usually not allowed in case of dichotomous data such as those of the PER, Monte
Carlo studies have shown that it is permissible to use ANOVA under certain conditions (Lunney 1970), which were met by the two experiments reported here. When necessary, Tukey tests were used to perform post hoc comparisons. The alpha level was set to 0.05 for all analyses.

\section{ACKNOWLEDGMENTS}

We thank Bernhard Komischke, Dagmar Malun, and Jean-Christophe Sandoz for helpful discussions. We especially thank Randolf Menzel for encouragement and valuable support. This work was supported by grants DFG La 564/10-1, DFG La 564/10-3, DFG Me 365/23-1, and DFG Gi 291/3-1 of the National German Science Foundation (DFG) and by grants from the Programme Action Cognitique of the French Research Agency, the Fondation pour la Recherche Médicale (France), and the Human Frontier Science Program (Young Investigator Grant) to Martin Giurfa.

The publication costs of this article were defrayed in part by payment of page charges. This article must therefore be hereby marked "advertisement" in accordance with 18 USC section 1734 solely to indicate this fact.

\section{REFERENCES}

Bitterman, M.E., Menzel, R., Fietz, A., and Schäfer, S. 1983. Classical conditioning of proboscis extension in honeybees (Apis mellifera). $J$. Comp. Psychol. 97: 107-119.

Deisig, N., Lachnit, H., Giurfa, M., and Hellstern, F. 2001. Configural olfactory learning in honeybees: Negative and positive patterning discrimination. Learn. Mem. 8: 70-78.

Erber, J., Kierzek, S., Sander, E., and Grandy, K. 1998. Tactile learning in the honeybee. J. Comp. Physiol. A 183: 737-744.

Galizia, C.G. and Menzel, R. 2000. Odour perception in honeybees: Coding information in glomerular patterns. Curr. Opin. Neurobiol. 10: 504-510.

Giurfa, M. and Lehrer M. 2001. Honeybee vision and floral displays: From detection to close-up recognition. In Cognitive ecology of pollination (eds. L. Chittka and J. Thomson), pp. 61-82. Cambridge University Press, Cambridge, UK.

Giurfa, M. and Menzel, R. 1997. Insect visual perception: Complex ability of simple nervous systems. Curr. Opin. Neurobiol. 7: 505-513.

Joerges, J., Küttner, A., Galizia, C.G., and Menzel, R. 1997. Representations of odors and odor mixtures visualized in the honeybee brain. Nature 387: 285-288.

Lachnit, H., Lober, K., Reinhard, G., and Kinder, A. 2001. Evidence for the application of rules in Pavlovian electrodermal conditioning with humans. Biol. Psychol. 56: 151-166.

Laska, M., Galizia, C.G., Giurfa, M., and Menzel, R. 1999. Olfactory discrimination ability and odor structure-activity relationships in honeybees. Chem. Senses 24: 429-438.

Lunney, G.H. 1970. Using analysis of variance with a dichotomous dependent variable: An empirical study. J. Educat. Meas. 7: 263-269.

Menzel, R. 1985. Learning in honey bees in an ecological and behavioral context. In Experimental behavioral ecology (eds. B. Hölldobler and M. Lindauer), pp. 55-74. Fischer, Stuttgart, Germany.

Menzel, R. 1999. Memory dynamics in the honeybee. J. Comp. Physiol. A 185: 323-340.

Menzel, R. and Giurfa, M. 2001. Cognitive architecture of a minibrain: The honeybee. Trends Cogn. Sci. 5: 62-71.

Menzel, R. and Müller, U. 1996. Learning and memory in honeybees: From behavior to neural substrates. Annu. Rev. Neurosci. 19: 379-404.

Menzel, R., Greggers, U., and Hammer, M. 1993. Functional organization of appetitive learning and memory in a generalist pollinator, the honey bee. In Insect learning: Ecological and evolutionary perspectives (eds. D. Papaj and A.C. Lewis), pp. 79-125. Chapman and Hall, New York.

Pearce, J.M. 1987. A model of stimulus generalization in Pavlovian conditioning. Psychol. Rev. 94: 61-73.

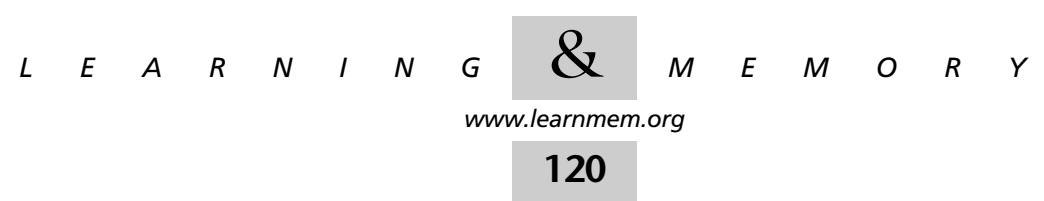


1994. Similarity and discrimination: A selective review and a connectionist model. Psychol. Rev. 101: 587-607.

Pelz, C., Gerber, B., and Menzel, R. 1997. Odorant intensity as a determinant for olfactory conditioning in honeybees: Roles in discrimination, overshadowing, and memory consolidation. J. Exp. Biol. 200: 837-847.

Rescorla, R.A. 1972. Configural conditioning in discrete-trial bar pressing. J. Comp. Physiol. Psychol. 79: 307-317.

. 1973. Evidence for unique stimulus account of configural conditioning. J. Comp. Physiol. Psychol. 85: 331-338.

Rescorla, R.A. and Wagner, A.R. 1972. A theory of Pavlovian conditioning: Variations in the effectiveness of reinforcement and nonreinforcement In Classical conditioning 2: Current research and theory (eds. A.H. Black and W.F. Prokasy), pp.64-99. Appleton-Century-Crofts, New York.
Takeda, K. 1961. Classical conditioned response in the honey bee. $J$. Insect Physiol. 6: 168-179.

Vareschi, R. 1971. Duftunterscheidung bei der Honigbiene: Einzelzell-Ableitungen und Verhaltensreaktionen. Z. vergl. Physiol. 75: 153-173.

Whitlow, J.W. and Wagner, A.R. 1972. Negative patterning in classical conditioning: Summation of response tendencies to isolable and configural components. Psychonom. Sci. 27: 299-301.

Williams, D.A. and Braker, D.S. 1999. Influence of past experience on the coding of compound stimuli. J. Exp. Psychol. Anim. Behav. Proc. 25: 461-474.

Received May 4, 2001; accepted in revised form April 16, 2002. 


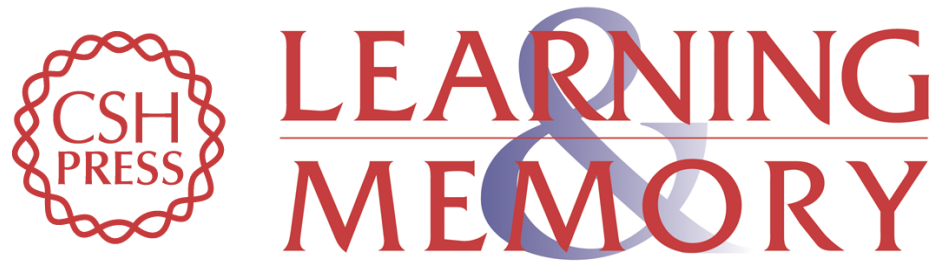

\section{The Effect of Similarity between Elemental Stimuli and Compounds in Olfactory Patterning Discriminations}

Nina Deisig, Harald Lachnit and Martin Giurfa

Learn. Mem. 2002, 9:

Access the most recent version at doi:10.1101/lm.41002

References This article cites 19 articles, 2 of which can be accessed free at: http://learnmem.cshlp.org/content/9/3/112.full.html\#ref-list-1

License

Email Alerting Receive free email alerts when new articles cite this article - sign up in the box at the Service top right corner of the article or click here. 